\title{
RING BERSIH KANAN
}

\author{
Cyrenia Novella Krisnamurti \\ Program Studi Pendidikan Matematika FKIP USD \\ Kampus III Paingan, Maguwoharjo,Sleman, cyrenianovella@gmail.com
}

\begin{abstract}
ABSTRAK
Penelitian ini bertujuan untuk mengenal, memahami dan menunjukkan bahwa sifat-sifat pada ring bersih berlaku untuk ring bersih kanan. Ring bersih kanan merupakan perluasan dari suatu ring bersih. Sifat-sifat dalam ring bersih berlaku juga pada ring bersih kanan.

Penelitian ini merupakan penelitian studi pustaka. Hal-hal yang akan dibahas untuk mendukung tentang sifat-sifat ring bersih kanan sebelumnya akan dibahas tentang dekomposisi Pierce dan matrik yang diperumum, mempelajari tentang ring bersih dan sifat-sifat ring bersih kanan.

Penelitian ini menghasilkan beberapa hal yaitu : Setiap ring yang dibangun dari elemenelemen idempoten adalah ring bersih kanan jika hanya jika ring utamanya merupakan ring bersih kanan, setiap ring yang merupakan gabungan himpunan semua elemen unit kiri, himpunan semua elemen unit kanan dan himpunan semua elemen nilpoten merupakan ring bersih kanan dan ring bersih kiri, setiap ring matriks atas ring bersih kanan merupakan ring bersih kanan.
\end{abstract}

Kata kunci : idempotent orthogonal lengkap, unit kanan, nilpotent, ring bersih kanan.

\begin{abstract}
This study aims to recognize, understand and demonstrate that the properties of the clean able to right clean rings. Right clean ring are explained clean rings. The properties of the clean rings also can be able to right clean rings.

This research based to study literature. $\mathrm{T}$ hings that will be discussed for support of the properties right clean rings before will be discussed on Pierce decomposition and generalized matrix, learn about the ring clean and properties of right clean rings.

The study produced several things: Each ring is constructed from elements idempotent are right clean rings if only if the ring is primarily right clean rings, each ring which is a combined set of all elements of the left unit, the set of all elements of the right unit and the set of all elements nilpotent a right clean ring and left clean ring, each ring matrix over right clean ring is right clean ring.
\end{abstract}

Key words : orthogonal idempotenst, right unit, nilpotent,right clean rings.

\section{Pendahuluan}

Ring merupakan struktur aljabar yang terhadap operasi penjumlahan merupakan grup abelian, terhadap operasi perkalian merupakan semigrup serta terhadap operasi perkalian dan penjumlahan bersifat distributif. Secara umum, dalam tulisan ini ring yang digunakan merupakan ring yang mempunyai elemen satuan. Ring dengan elemen satuan mempunyai elemenelemen istimewa di antaranya elemen idempoten dan elemen unit. 
Pada ring dengan elemen satuan, suatu elemen disebut elemen bersih jika elemen tersebut merupakan hasil dari penjumlahan dari elemen idempoten dan elemen unit. Contoh dari elemen bersih adalah elemen $\overline{0}$ pada ring $\mathbf{Z}_{6}$ karena $\overline{0}=\overline{1}+\overline{5} \quad$ dimana $\quad \overline{1}$ adalah elemen idempoten dari ring $\mathbf{Z}_{6}$ dan $\overline{5}$ adalah elemen unit di $\operatorname{ring} \mathbf{Z}_{6}$.

Secara umum, ring $R$ disebut ring bersih jika untuk setiap $r \in R$ berlaku $r=e+u$, untuk suatu elemen idempoten $e$ dan elemen unit $u$. Contoh dari ring bersih adalah ring $\mathbf{Z}_{6}$, karena setiap elemen dari ring $\mathbf{Z}_{6}$ dapat dinyatakan sebagai penjumlahan dari elemen idempoten dan elemen unit.

Pada umumnya tidak semua ring mempunyai elemen unit dua sisi. Jika $R$ adalah ring yang mempunyai elemen unit satu sisi, elemen yang dapat dinyatakan sebagai jumlah elemen unit satu sisi(kanan/kiri) dan elemen idempoten disebut elemen bersih kanan/kiri. Suatu ring yang elemen-elemennya merupakan elemen bersih satu sisi (kanan/kiri) disebut ring bersih satu sisi. Definisi dan sifat-sifat dari ring bersih satu sisi dikenalkan oleh Călugăreanu pada tahun 2010. Demikian juga untuk modul juga terdapat modul yang bersifat bersih satu sisi.

\section{Metode Penelitian}

Penelitian ini dilakukan dengan studi literatur dari beberapa buku dan artikel ilmiah yang berhubungan dengan ring, ring bersih dan ring bersih kanan. Langkah-langkah penelitian yang dilakukan sebagai berikut :

1. Mempelajari tentang dekomposisi Pierce dan matriks yang diperumum.

2. Mempelajari tentang ring bersih dan sifat-sifat yang berlaku pada ring bersih.

3. Mempelajari tentang ring bersih kanan dan sifat-sifat yang berlaku pada ring bersih kanan.

\section{Hasil dan Pembahasan}

Ring bersih kanan adalah kejadian yang lebih umum dari ring bersih. Berikut definisi dari ring bersih kanan.

\section{Definisi 1 (Călugăreanu, 2010)}

Diberikan ring $R$. Ring $R$ disebut ring bersih kanan apabila setiap elemen dari ring tersebut dapat dinyatakan sebagai penjumlahan dari suatu elemen idempoten dan suatu elemen unit kanan di R.

Selanjutnya himpunan semua unit kanan dari suatu ring dinotasikan $U_{r}(R)$ - Berikut diberikan suatu sifat dari ring bersih kanan.

Lemma 2 (Călugăreanu, 2010) 
Diketahui $R$ dan $S$ adalah ring bersih kanan. Jika pemetaan $\theta: R \rightarrow S$ suatu epimorfisma maka $\operatorname{Im}(\theta) \subseteq S$ adalah ring bersih kanan.

1. Diketahui $R$ adalah ring bersih kanan. Hasil kali $\prod R_{i}$ merupakan ring bersih kanan jika dan hanya jika $R_{i}$ adalah ring bersih kanan untuk setiap $i \in I$.

\section{Bukti :}

1. Diambil sebarang $x \in \operatorname{Im}(\theta)$. Oleh karena itu terdapat pemetaan $\theta: R \rightarrow S \quad$ suatu epimorfisma sehingga $\theta(r)=x$. Karena $R$ adalah ring bersih kanan maka $r=u_{R}+a_{R}$ dengan $u_{R} \in U_{r}(R)$ dan $a \in I d(R)$, sehingga $\theta(r)=\theta\left(u_{R}+a_{R}\right)$. Karena $\theta$ adalah homomorfisma diperoleh

$$
\theta\left(u_{R}+a_{R}\right)=\theta\left(u_{R}\right)+\theta\left(a_{R}\right)
$$

Akan ditunjukkan bahwa $\theta(r)=u_{S}+a_{S} \quad$ dengan $\quad u_{S} \in U_{r}(S)$ dan $a \in \operatorname{Id}(S)$.

a. $\operatorname{Im}(\theta)$ memuat elemen unit.

Karena $\theta$ adalah epimorfisma dan $u_{R} \in R$ dan $R$ adalah ring dengan elemen satuan maka jelas bahwa $\theta\left(u_{R}\right)=u_{S} . \quad$ Sehingga $\operatorname{Im}(S)$ memuat elemen unit di $S$. b. $\operatorname{Im}(\theta)$ memuat elemen idempotent.

Karena $R$ adalah ring bersih kanan berarti $R$ memuat elemen idempotent. Diambil sebarang $a_{R} \in R$ adalah elemen idempotent di $R$ sehingga $a_{R}=a_{R} \cdot a_{R}$. Karena $\theta$ adalah homomorfisma ring, sehingga

$$
\theta\left(a_{R}\right)=\theta\left(a_{R} \cdot a_{R}\right)=\theta\left(a_{R}\right) \cdot \theta\left(a_{R}\right)
$$

Karena $\theta\left(a_{R}\right)=a_{S}$ maka diperoleh bahwa $a_{S}=a_{S} \cdot a_{S} . \quad$ Sehingga $\operatorname{Im}(S)$ memuat elemen idempotent di $S$.

Dari a dan b maka

$\theta(r)=\theta\left(u_{R}+a_{R}\right)$

$\theta(r)=\theta\left(u_{R}\right)+\theta\left(a_{R}\right)$

$\theta(r)=u_{S}+a_{S}$.

Sehingga $\operatorname{Im}(\theta) \subseteq S$ adalah ring bersih kanan.

2. $\prod R_{i}$ adalah ring bersih kanan jika dan hanya jika $R_{i}$ adalah ring bersih kanan untuk setiap $i \in I$.

a. $\Rightarrow)$ Akan ditunjukkan jika $\prod R_{i}$ adalah ring bersih kanan maka $R_{i}$ adalah ring bersih kanan untuk setiap $i \in I$.

$\prod R_{i}=\left(r_{\alpha}\right)_{\alpha \in I} \quad$ dengan $\quad r_{i} \in R$ atau dapat dinyatakan 
$\prod R_{i}=\left(r_{\alpha}\right)_{\alpha \in I}$ adalah ring bersih kanan sehingga

$\left(r_{\alpha}\right)_{\alpha \in I}=\left(u_{\alpha}\right)_{\alpha \in I}+\left(a_{\alpha}\right)_{\alpha \in I}$

dimana $\quad u_{\alpha} \in U_{r}(R) \quad$ dan

$a_{\alpha} \in \operatorname{Id}(R)$

$\left(r_{\alpha}\right)_{\alpha \in I}=\left(u_{\alpha}\right)_{\alpha \in I}+\left(a_{\alpha}\right)_{\alpha \in I}$

menurut definisi penjumlahan pada system barisan diperoleh

$\left(r_{\alpha}\right)_{\alpha \in I}=\left(u_{\alpha}+a_{\alpha}\right)_{\alpha \in I}$

Dengan menggunakan definisi persamaan dalam sistem barisan diperoleh

$r_{\alpha}=u_{\alpha}+a_{\alpha}$ dimana $u_{\alpha} \in U_{r}(R)$

dan $a_{\alpha} \in I d(R)$. Maka $R_{i}$ adalah

ring bersih kanan.

b. $\Leftarrow)$ Akan ditunjukkan jika $R_{i}$ ring bersih kanan untuk setiap $i \in I$ maka $\prod R_{i}$ adalah ring bersih kanan .

Diambil sebarang barisan $\left(r_{i}\right)_{i \in I}$ dengan $r_{i} \in R_{i}$. Karena diketahui bahwa $R_{i}$ adalah ring bersih kanan maka $r_{i}=u_{i}+a_{i}$ dengan $u_{i} \in U_{r}\left(R_{i}\right) \quad$ adalah dan $a_{i} \in I d\left(R_{i}\right) . \quad$ Dilain pihak $\left(r_{i}\right)_{i \in I}=\left(u_{i}+a_{i}\right)_{i \in I} \quad$ menurut definisi penjumlahan pada sistem barisan

diperoleh

$$
\left(r_{i}\right)_{i \in I}=\left(u_{i}\right)_{i \in I}+\left(a_{i}\right)_{i \in I} .
$$

Sehingga diperoleh $\prod R_{i}$ adalah ring bersih kanan.

Dari a dan b terbukti.

Dari 1 dan 2 Lemma terbukti.

Berikut diberikan teorema yang menjelaskan tentang ring yang dibangun oleh ring bersih kanan merupakan ring bersih kanan.

\section{Teorema 3 (Călugăreanu, 2010)}

Diberikan ring $A, B$, bimodul ${ }_{A} C_{B}$ dan $R=\left[\begin{array}{ll}A & C \\ 0 & B\end{array}\right] \quad$ dengan operasi penjumlahan dan perkalian pada matriks. Ring $R$ adalah ring bersih kanan jika dan hanya jika ring $A$ dan $B$ adalah ring bersih kanan.

Bukti :

1. $\Rightarrow)$ Akan ditunjukkan jika $R=\left[\begin{array}{ll}A & C \\ 0 & B\end{array}\right]$ adalah ring bersih kanan maka ring $A$ dan $B$ adalah ring bersih kanan.

Dibentuk suatu pemetaan $f$ dari $R$ ke $A$ yang didefiniskan $f: R \rightarrow A$ dengan definisi pemetaan $f\left(\left[\begin{array}{ll}a & c \\ 0 & b\end{array}\right]\right)=a$, dan $g$ dari $R$ ke $B$ yang didefiniskan $g: R \rightarrow B$ dengan 
definisi pemetaan $g\left(\left[\begin{array}{ll}a & c \\ 0 & b\end{array}\right]\right)=b$ dengan $a \in A, b \in B \quad$ dan $\quad c \in C$. Untuk menunjukkan bahwa ring $A$ dan $B$ adalah ring bersih kanan cukup dengan membuktikan bahwa $f, g$ merupakan epimorfisma.

a. Akan ditunjukkan $f$ epimorfisma yaitu

i. Akan ditunjukkan $f$ terdefinisi dengan baik.

Diambil sebarang $A_{1}, A_{2} \in R$. Hal ini berarti $A_{1}=\left[\begin{array}{cc}a_{1} & c_{1} \\ 0 & b_{1}\end{array}\right]$ dan $A_{2}=\left[\begin{array}{cc}a_{2} & c_{2} \\ 0 & b_{2}\end{array}\right]$ dengan $a_{1}, a_{2} \in A, \quad b_{1}, b_{2} \in B \quad$ dan $c_{1}, c_{2} \in C \quad$ dengan $A_{1}=A_{2}$.

Menurut kesamaan 2 matriks maka $a_{1}=a_{2}, \quad b_{1}=b_{2} \quad$ dan $c_{1}=c_{2}$.

$f\left(\left[\begin{array}{ll}a_{1} & c_{1} \\ 0 & b_{1}\end{array}\right]\right)=a_{1} \quad$, karena

$a_{1}=a_{2}$ maka diperoleh

$f\left(\left[\begin{array}{ll}a_{1} & c_{1} \\ 0 & b_{1}\end{array}\right]\right)=a_{2}$

$f\left(\left[\begin{array}{cc}a_{1} & c_{1} \\ 0 & b_{1}\end{array}\right]\right)=f\left(\left[\begin{array}{cc}a_{2} & c_{2} \\ 0 & b_{2}\end{array}\right]\right)$.

$f\left(A_{1}\right)=f\left(A_{2}\right)$.

ii. Akan ditunjukkan homomorfisma
Diambil sebarang $A_{1}, A_{2} \in R$ berarti $A_{1}=\left[\begin{array}{cc}a_{1} & c_{1} \\ 0 & b_{1}\end{array}\right]$ dan $A_{2}=\left[\begin{array}{cc}a_{2} & c_{2} \\ 0 & b_{2}\end{array}\right] \quad$ dengan $a_{1}, a_{2} \in A, \quad b_{1}, b_{2} \in B \quad$ dan $c_{1}, c_{2} \in C . \quad$ Diperhatikan bahwa, $f\left(A_{1}+A_{2}\right)=f\left(\left[\begin{array}{cc}a_{1} & c_{1} \\ 0 & b_{1}\end{array}\right]+\left[\begin{array}{cc}a_{2} & c_{2} \\ 0 & b_{2}\end{array}\right]\right)$ $f\left(A_{1}+A_{2}\right)=f\left(\left[\begin{array}{cc}a_{1}+a_{2} & c_{1}+c_{2} \\ 0 & b_{1}+b_{2}\end{array}\right]\right)$ $f\left(A_{1}+A_{2}\right)=a_{1}+a_{2}$ $f\left(A_{1}+A_{2}\right)=f\left(\left[\begin{array}{cc}a_{1} & c_{1} \\ 0 & b_{1}\end{array}\right]\right)+f\left(\left[\begin{array}{cc}a_{2} & c_{2} \\ 0 & b_{2}\end{array}\right]\right)$ $f\left(A_{1}+A_{2}\right)=f\left(A_{1}\right)+f\left(A_{2}\right)$. Selanjutnya, diambil sebarang $\alpha \in A$ dan $A_{1} \in R$. Hal ini berarti $A_{1}=\left[\begin{array}{cc}a_{1} & c_{1} \\ 0 & b_{1}\end{array}\right]$ dengan $a_{1} \in A \quad, \quad b_{1} \in B \quad, \quad c_{1} \in C$.

Diperhatikan bahwa,

$$
\begin{aligned}
& f\left(\alpha \cdot A_{1}\right)=f\left(\alpha \cdot\left[\begin{array}{ll}
a_{1} & c_{1} \\
0 & b_{1}
\end{array}\right]\right) \\
& f\left(\alpha \cdot A_{1}\right)=f\left(\left[\begin{array}{cc}
\alpha \cdot a_{1} & \alpha \cdot c_{1} \\
0 & \alpha \cdot b_{1}
\end{array}\right]\right) \\
& f\left(\alpha \cdot A_{1}\right)=\alpha \cdot a_{1}
\end{aligned}
$$




$$
\begin{aligned}
& f\left(\alpha \cdot A_{1}\right)=\alpha \cdot f\left(\left[\begin{array}{ll}
a_{1} & c_{1} \\
0 & b_{1}
\end{array}\right]\right) \\
& f\left(\alpha \cdot A_{1}\right)=\alpha \cdot f\left(A_{1}\right) .
\end{aligned}
$$

iii. Akan ditunjukkan $f$ surjektif.

Diambil sebarang $a_{1} \in A$ menurut definisi pemetaan $f: R \rightarrow A$ maka terdapat $a_{1} \in A$ yang mengakibatkan $A_{1}=\left[\begin{array}{cc}a_{1} & c_{1} \\ 0 & b_{1}\end{array}\right] \in R$ untuk suatu $b_{1} \in B$ dan $c_{1} \in C$ sehingga $f\left(A_{1}\right)=a_{1}$.

Jadi terbukti bahwa $f$ surjektif. Dari i, ii, dan iii diperoleh bahwa $f$ epimorfisma.

b. Akan ditunjukkan $g$ epimorfisma

i. Akan ditunjukkan $g$ terdefinisi dengan baik.

Diambil sebarang $B_{1}, B_{2} \in R$. Hal ini berarti $B_{1}=\left[\begin{array}{cc}a_{1} & c_{1} \\ 0 & b_{1}\end{array}\right]$ dan $\quad B_{2}=\left[\begin{array}{cc}a_{2} & c_{2} \\ 0 & b_{2}\end{array}\right]$ dengan $a_{1}, a_{2} \in A, \quad b_{1}, b_{2} \in B \quad$ dan $c_{1}, c_{2} \in C \quad$ dengan $B_{1}=B_{2}$. Menurut kesamaan 2 matrik maka $a_{1}=a_{2}, \quad b_{1}=b_{2} \quad$ dan $c_{1}=c_{2}$. $g\left(\left[\begin{array}{cc}a_{1} & c_{1} \\ 0 & b_{1}\end{array}\right]\right)=b_{1} \quad$, karena $b_{1}=b_{2}$ maka diperoleh

$$
\begin{aligned}
& g\left(\left[\begin{array}{ll}
a_{1} & c_{1} \\
0 & b_{1}
\end{array}\right]\right)=b_{2} \\
& g\left(\left[\begin{array}{ll}
a_{1} & c_{1} \\
0 & b_{1}
\end{array}\right]\right)=g\left(\left[\begin{array}{cc}
a_{2} & c_{2} \\
0 & b_{2}
\end{array}\right]\right) . \\
& g\left(B_{1}\right)=g\left(B_{2}\right) .
\end{aligned}
$$

ii. Akan ditunjukkan $g$ homomorfisma

Diambil sebarang $B_{1}, B_{2} \in R$.

Hal ini berarti $B_{1}=\left[\begin{array}{cc}a_{1} & c_{1} \\ 0 & b_{1}\end{array}\right]$ dan $\quad B_{2}=\left[\begin{array}{cc}a_{2} & c_{2} \\ 0 & b_{2}\end{array}\right]$ dengan $a_{1}, a_{2} \in A, \quad b_{1}, b_{2} \in B \quad$ dan $c_{1}, c_{2} \in C . \quad$ Diperhatikan bahwa

$$
\begin{aligned}
& g\left(B_{1}+B_{2}\right)=g\left(\left[\begin{array}{cc}
a_{1} & c_{1} \\
0 & b_{1}
\end{array}\right]+\left[\begin{array}{cc}
a_{2} & c_{2} \\
0 & b_{2}
\end{array}\right]\right) \\
& g\left(B_{1}+B_{2}\right)=g\left(\left[\begin{array}{cc}
a_{1}+a_{2} & c_{1}+c_{2} \\
0 & b_{1}+b_{2}
\end{array}\right]\right)
\end{aligned}
$$$$
g\left(B_{1}+B_{2}\right)=b_{1}+b_{2}
$$$$
g\left(B_{1}+B_{2}\right)=g\left(\left[\begin{array}{cc}
a_{1} & c_{1} \\
0 & b_{1}
\end{array}\right]\right)+g\left(\left[\begin{array}{cc}
a_{2} & c_{2} \\
0 & b_{2}
\end{array}\right]\right)
$$

$$
g\left(B_{1}+B_{2}\right)=g\left(A_{1}\right)+g\left(A_{2}\right) .
$$

Selanjutnya diambil sebarang $\beta \in B \quad$ dan $\quad B_{1} \in R \quad$ berarti 


$$
\begin{aligned}
& B_{1}=\left[\begin{array}{ll}
a_{1} & c_{1} \\
0 & b_{1}
\end{array}\right] \text { dengan } a_{1} \in A \\
& , \quad b_{1} \in B \quad, \quad c_{1} \in C .
\end{aligned}
$$

Diperhatikan bahwa,

$$
\begin{aligned}
& g\left(\beta . B_{1}\right)=g\left(\beta \cdot\left[\begin{array}{ll}
a_{1} & c_{1} \\
0 & b_{1}
\end{array}\right]\right) \\
& g\left(\beta \cdot B_{1}\right)=g\left(\left[\begin{array}{cc}
\beta \cdot a_{1} & \beta \cdot c_{1} \\
0 & \beta \cdot b_{1}
\end{array}\right]\right) \\
& g\left(\beta . B_{1}\right)=\beta \cdot b_{1} \\
& g\left(\beta . B_{1}\right)=\beta \cdot g\left(\left[\begin{array}{ll}
a_{1} & c_{1} \\
0 & b_{1}
\end{array}\right]\right) \\
& g\left(\beta . B_{1}\right)=\beta \cdot g\left(B_{1}\right) .
\end{aligned}
$$

iii. Akan ditunjukkan $g$ surjektif

Diambil sebarang $\quad b_{1} \in B$ menurut definisi pemetaan $g: R \rightarrow B$ maka terdapat terdapat $\quad b_{1} \in B \quad$ yang mengakibatkan

$$
\begin{aligned}
& B_{1}=\left[\begin{array}{cc}
a_{1} & c_{1} \\
0 & b_{1}
\end{array}\right] \in R \text { untuk suatu } \\
& a_{1} \in A \text { dan } c_{1} \in C \text { sehingga } \\
& \text { sedemikian } \quad \text { sehingga } \\
& g\left(B_{1}\right)=b_{1} .
\end{aligned}
$$

Jadi terbukti bahwa $g$ surjektif.

Dari i, ii, dan iii diperoleh bahwa $g$ epimorfisma

Jadi $f$ dan $g$ epimorfirma. Jelas bahwa $A$ dan $B$ adalah ring bersih kanan.
2. $\Leftarrow)$ Akan ditunjukkan berlaku jika ring $A$ dan $B$ adalah ring bersih kanan maka $R=\left[\begin{array}{ll}A & C \\ 0 & B\end{array}\right]$ adalah ring bersih kanan.

Diambil sebarang $r \in R$. Karena $R=\left[\begin{array}{cc}A & C \\ 0 & B\end{array}\right]$ maka $r=\left[\begin{array}{cc}a & c \\ 0 & b\end{array}\right]$ untuk suatu $a \in A, b \in B, c \in C$. Karena $A$ dan $B$ adalah ring bersih kanan. Hal ini berarti $a=u_{A}+e_{A}$ dengan $u_{A} \in U_{r}(A), \quad e_{A} \in I d(A) \quad$ dan $b=u_{B}+e_{B} \quad$ dengan $\quad u_{B} \in U_{r}(B)$, $e_{B} \in I d(B) . \quad$ Karena $\quad u_{A} \in U_{r}(A)$ berarti terdapat $v_{A} \in A$ sedemikian hingga $u_{A} \cdot v_{A}=1_{A} \quad$ dan karena $u_{B} \in U_{r}(B)$ berarti terdapat $v_{B} \in B$ sedemikian hingga $u_{B} \cdot v_{B}=1_{B}$. Perhatikan bahwa,

$$
\begin{aligned}
& r=\left[\begin{array}{ll}
a & c \\
0 & b
\end{array}\right] \\
& r=\left[\begin{array}{cc}
u_{A}+e_{A} & c \\
0 & u_{B}+e_{B}
\end{array}\right] \\
& r=\left[\begin{array}{cc}
u_{A} & c \\
0 & u_{B}
\end{array}\right]+\left[\begin{array}{cc}
e_{A} & 0_{C} \\
0 & e_{B}
\end{array}\right] .
\end{aligned}
$$

Selanjutnya, ditunjukkan bahwa $\left[\begin{array}{cc}u_{A} & c \\ 0 & u_{B}\end{array}\right]$ merupakan elemen unit 
kanan di $R$ dan $\left[\begin{array}{cc}e_{A} & 0_{C} \\ 0 & e_{B}\end{array}\right]$ merupakan

elemen idempotent di $R$.

i. Diperhatikan bahwa,

$\left[\begin{array}{cc}e_{A} & 0_{C} \\ 0 & e_{B}\end{array}\right] \cdot\left[\begin{array}{cc}e_{A} & 0_{C} \\ 0 & e_{B}\end{array}\right]=\left[\begin{array}{cc}e_{A} \cdot e_{A} & 0_{C} \\ 0 & e_{B} \cdot e_{B}\end{array}\right]$

- Karena $e_{A} \in \operatorname{Id}(A)$ dan

$e_{B} \in I d(B)$ maka

$\left[\begin{array}{cc}e_{A} & 0_{C} \\ 0 & e_{B}\end{array}\right] \cdot\left[\begin{array}{cc}e_{A} & 0_{C} \\ 0 & e_{B}\end{array}\right]=\left[\begin{array}{cc}e_{A} & 0_{C} \\ 0 & e_{B}\end{array}\right]$.

$\operatorname{Jadi}\left[\begin{array}{cc}e_{A} & 0_{C} \\ 0 & e_{B}\end{array}\right] \in I d(R)$.

ii. Apakah $\left[\begin{array}{cc}u_{A} & c \\ 0 & u_{B}\end{array}\right]$ merupakan

elemen unit kanan di $R$ ?

Berarti terdapat $v \in R$ sedemikian sehingga $u_{R} \cdot v_{R}=1 . v \in R$ berarti $v_{R}=\left[\begin{array}{ll}s & t \\ x & y\end{array}\right] \quad$ sehingga $\left[\begin{array}{cc}u_{A} & c \\ 0 & u_{B}\end{array}\right] \cdot\left[\begin{array}{ll}s & t \\ x & y\end{array}\right]=\left[\begin{array}{ll}1 & 0 \\ 0 & 1\end{array}\right]$ $\left[\begin{array}{cc}u_{A} \cdot s+c \cdot x & u_{A} \cdot t+c \cdot y \\ u_{B} \cdot x & u_{B} \cdot y\end{array}\right]=\left[\begin{array}{ll}1 & 0 \\ 0 & 1\end{array}\right]$

Menurut kesamaan 2 matriks maka diperoleh

$u_{A} . s+c . x=1$

(i)

$u_{B} \cdot x=0$

$u_{A} . t+c . y=0$
$u_{B} \cdot y=1$

Dari persamaan (ii) maka diperoleh bahwa $x=0$, dari persamaan (iv) maka diperoleh bahwa $y=v_{B}$.

Dari persamaan (i) dan $x=0$ maka diperoleh $s=v_{A}$.

Dari persamaan (iii) maka diperoleh bahwa

$u_{A} \cdot t+c . y=0$

$u_{A} \cdot t+c \cdot v_{B}=0$

$t=\left(-v_{A} \cdot c\right) \cdot v_{B}$

Dari hasil diatas maka diperoleh $\left[\begin{array}{ll}s & t \\ x & y\end{array}\right]=\left[\begin{array}{cc}v_{A} & \left(-v_{A} \cdot c\right) \cdot v_{B} \\ 0_{R} & v_{B}\end{array}\right]$.

Maka diperoleh bahwa $\left[\begin{array}{cc}u_{A} & c \\ 0 & u_{B}\end{array}\right]$ merupakan elemen unit kanan di $R$.

Dari i dan ii jelas bahwa $R=\left[\begin{array}{ll}A & C \\ 0 & B\end{array}\right]$ adalah ring bersih kanan.

Dari 1 dan 2 teorema terbukti.

Ring dengan elemen satuan terdapat paling tidak terdapat dua elemen idempoten. Elemen-elemen idempoten dapat membangun struktur ring baru. Berikut ini, terdapat teorema yang 
menyatakan bahwa ring bersih kanan yang dibangun oleh elemen-elemen idempotent merupakan ring bersih kanan.

Teorema 4 (Călugăreanu, 2010)

Diberikan ring $R$ dengan mempunyai elemen idempoten e dan $(1-e)$. Jika eRe dan $(1-e) R(1-e)$ adalah ring bersih kanan maka $R$ merupakan ring bersih kanan.

Bukti :

Karena

$$
e+(1-e)=1
$$

dan

$e(1-e)=e-e e=e-e=0$, maka $e$ dan

$(1-e)$ merupakan elemen idempoten orthogonal lengkap diperoleh :

$$
R \cong\left[\begin{array}{cc}
e R e & e R(1-e) \\
(1-e) \operatorname{Re} & (1-e) R(1-e)
\end{array}\right] .
$$

Diambil sebarang

$\left[\begin{array}{ll}a & x \\ y & b\end{array}\right] \in\left[\begin{array}{cc}e R e & e R(1-e) \\ (1-e) \operatorname{Re} & (1-e) R(1-e)\end{array}\right]$.

Hal ini berarti $a \in e R e ; x \in e R(1-e)$; $y \in(1-e) R e ; \operatorname{dan} b \in(1-e) R(1-e)$. Karena ring $e R e$ adalah ring bersih kanan maka $a=u+f \quad$ dengan $u \in U_{r}(e R e)$ dan $f \in I d(e R e)$. Karena ring $(1-e) R(1-e)$ adalah ring bersih kanan maka $b=v+g$ dengan $v \in U_{r}((1-e) R(1-e))$ dan $g \in I d((1-e) R(1-e))$.
Karena $\quad x \in e R(1-e) \quad$ maka $x=e r_{1}(1-e) \quad$ untuk $\quad$ suatu $\quad r_{1} \in R$ ..(i) dan $y \in(1-e) R e$ maka $y=(1-e) r_{2} e$ untuk suatu $r_{2} \in R$

(ii).

Karena $u \in U_{r}(e R e)$ maka terdapat $u^{-1} \in e R e$ berarti $u^{-1}=e r_{3} e$ untuk suatu $r_{3} \in R$

Dari persamaan i, ii dan iii, diperoleh

$$
\begin{aligned}
y u^{-1} x & =\left((1-e) r_{2} e\right)\left(e r_{3} e\right)\left(e r_{1}(1-e)\right) \\
y u^{-1} x & =(1-e)\left(r_{2} e r_{3}\right)\left(e r_{1}(1-e)\right) \\
y u^{-1} x & =(1-e)\left(r_{2} e r_{3} e r_{1}\right)(1-e)
\end{aligned}
$$

Karena $r_{2} \in R ; e \in R ; r_{3} \in R ; r_{1} \in R$ maka $r_{2} . e r_{3}$ e. $r_{1} \in R$ sehingga diperoleh bahwa $y u^{-1} x \in(1-e) R(1-e)$. Lebih lanjut lagi, karena $b \in(1-e) R(1-e)$. Karena $(1-e) R(1-e)$ suatu ring sehingga $b-y \cdot u^{-1} . x \in(1-e) R(1-e)$.

Berdasarkan asumsi, $\quad(1-e) R(1-e)$ merupakan ring bersih kanan. Oleh karena itu, $\quad b-y u^{-1} x=v+g$ dengan $v \in U_{r}((1-e) R(1-e))$ dan $g \in I d((1-e) R(1-e))$. Akibatnya $b=v+g+y \cdot u^{-1} \cdot x$.

Dengan demikian,

$\left[\begin{array}{ll}a & x \\ y & b\end{array}\right]=\left[\begin{array}{cc}u+f & x \\ y & v+g+y \cdot u^{-1} \cdot x\end{array}\right]$ 
$\left[\begin{array}{ll}a & x \\ y & b\end{array}\right]=\left[\begin{array}{cc}u & x \\ y & v+y \cdot u^{-1} \cdot x\end{array}\right]+\left[\begin{array}{ll}f & 0 \\ 0 & g\end{array}\right]$.

Sekarang tinggal ditunjukkan $\left[\begin{array}{cc}u & x \\ y & v+y \cdot u^{-1} . x\end{array}\right] \in U_{r}(R) . \quad$ Hal ini berarti $\left[\begin{array}{cc}u & x \\ y & v+y \cdot u^{-1} \cdot x\end{array}\right] \quad$ mempunyai invers di $R$. Untuk mencari invers dari matriks tersebut menggunakan metode operasi baris elementer. Karena ring $R$ adalah ring dengan elemen satuan maka diperoleh elemen satuan dari $R$ adalah $\left[\begin{array}{cc}e & 0 \\ 0 & (1-e)\end{array}\right]$. Perhatikan bahwa, $\left[\begin{array}{cc|cc}u & x & e & 0 \\ y & v+y \cdot u^{-1} . x & 0 & (1-e)\end{array}\right]$ dengan

menggunakan Operasi Baris Elementer diperoleh bahwa

bahwa $\left[\begin{array}{cc}u & x \\ y & v+y \cdot u^{-1} \cdot x\end{array}\right] \in U_{r}(R)$.

Sekarang tinggal menunjukkan bahwa $\left[\begin{array}{ll}f & 0 \\ 0 & g\end{array}\right] \in I d(R) . \quad$ Ekuivalen dengan menunjukkan

$$
\begin{aligned}
& {\left[\begin{array}{ll}
f & 0 \\
0 & g
\end{array}\right]=\left[\begin{array}{ll}
f & 0 \\
0 & g
\end{array}\right] \cdot\left[\begin{array}{ll}
f & 0 \\
0 & g
\end{array}\right] .} \\
& {\left[\begin{array}{ll}
f & 0 \\
0 & g
\end{array}\right] \cdot\left[\begin{array}{ll}
f & 0 \\
0 & g
\end{array}\right]=\left[\begin{array}{cc}
f \cdot f & 0 \\
0 & g \cdot g
\end{array}\right]}
\end{aligned}
$$

Karena $\quad f \in I d(e R e) \quad$ dan $g \in I d((1-e) R(1-e))$ maka $f . f=f$ dan $\quad g . g=g \quad$ sehingga $\left[\begin{array}{ll}f & 0 \\ 0 & g\end{array}\right] \cdot\left[\begin{array}{ll}f & 0 \\ 0 & g\end{array}\right]=\left[\begin{array}{ll}f & 0 \\ 0 & g\end{array}\right]$. Oleh karena itu, terbukti bahwa $\left[\begin{array}{ll}f & 0 \\ 0 & g\end{array}\right] \in \operatorname{Id}(R)$.

Jadi sebarang

$\left[\begin{array}{ll}a & x \\ y & b\end{array}\right] \in\left[\begin{array}{cc}e \operatorname{Re} & e R(1-e) \\ (1-e) \operatorname{Re} & (1-e) R(1-e)\end{array}\right]$

merupakan elemen bersih kanan. Hal ini berakibat

bahwa ring $R \cong\left[\begin{array}{cc}e \operatorname{Re} & e R(1-e) \\ (1-e) \operatorname{Re} & (1-e) R(1-e)\end{array}\right]$ maka bahwa $R$ merupakan ring bersih kanan.

Berikut diberikan suatu akibat bahwa ring matrik yang dibangun oleh ring bersih kanan merupakan ring bersih kanan.

\section{Akibat 5 (Călugăreanu, 2010)}

Jika $R$ adalah ring bersih kanan maka $M_{n \times n}(R)$ adalah ring bersih kanan.

Ring dengan elemen satuan mempunyai elemen-elemen istimewa sepeti elemen unit, elemen nilpotent. Himpunan gabungan dari himpunan unit kiri, unit kanan dan himpunan nilpotent dari ring tersebut merupakan ring bersih kanan sekaligus ring bersih kiri. Untuk lebih jelasnya berikut diberikan teorema yang menyatakan hal tersebut.

Teorema 6 (Călugăreanu, 2010) 
Setiap ring $R=U_{l}(R) \cup U_{r}(R) \cup N(R)$ adalah ring bersih kanan dan ring bersih kiri.

Bukti :

1. Akan ditunjukkan $R$ ring bersih kanan.

Diambil sebarang $\quad r \in R$ berarti $r \in U_{l}(R) \cup U_{r}(R) \cup N(R)$.

Misalkan $r \in U_{l}(R)$ berarti terdapat $s \in R$ yang memenuhi $s . r=1$ dan $r . s \in R$. Perhatikan bahwa,

$(r . s) .(r . s)=r .(s . r) . s$

$(r . s) .(r . s)=r .1 . s$

$(r . s) \cdot(r . s)=r . s$

Diperoleh bahwa (r.s) adalah elemen idempoten di $R$.

Karena (r.s) adalah elemen idempoten di $R$ dan diperoleh $(1-(r . s))$ juga merupakan elemen idempoten di $R$.

Selanjutnya, tinggal menunjukkan bahwa $(r+((r . s)-1))$ merupakan elemen unit kanan di $R$.

Dibentuk

$x=((r . s) s(r . s))+((r . s)-1) \in R$

sehingga diperoleh $(((r s) s(r s))+((r s)-1))(r+((r s)-1))=1$ $(1-r) \in U_{r}(R) . \quad$ Diperhatikan $(1-r) \in U_{r}(R) . \quad$ Diperhatikan

Sehingga terbukti bahwa $R$ adalah $r=1-(1-r)$. Karena $(1-r) \in R$ dan $R$ ring bersih kanan.

2. Akan ditunjukkan $R$ ring bersih kiri. Diambil sebarang $r \in R$ berarti $r \in U_{l}(R) \bigcup U_{r}(R) \bigcup N(R)$.

Misalkan $r \in U_{r}(R)$ berarti terdapat $s \in R$ sedemikian sehingga $r . s=1$ dan $s . r \in R$, maka $(s . r) .(s . r)=s(r . s) r$ $(s . r) .(s . r)=s .1 . r$ $(s . r) \cdot(s . r)=s . r$

Diperoleh bahwa (s.r)adalah elemen idempotent di $R$.

Karena (r.s) adalah elemen idempoten di $R$ dan diperoleh $(1-(r . s))$ juga merupakan elemen idempoten di $R$.

Tinggal ditunjukkan bahwa $(r+((s . r)-1))$ merupakan elemen unit kiri di $R$.

Dengan cara yang analog dengan (1) maka terbukti bahwa $R$ adalah ring bersih kiri.

Sekarang diambil sebarang $r \in N(R)$ berarti $r^{n}=0$ untuk $n \in \square$. Persamaan $r^{n}=0 \quad$ ekuivalen dengan $(1-r)\left(1+r+r^{2}+\ldots+r^{n-1}\right)=1 . \quad$ Karena $(1-r)\left(1+r+r^{2}+\ldots+r^{n-1}\right)=1 \quad$ maka 
adalah ring maka $(-(1-r)) \in R$, sehingga diperoleh $r=1+(-(1-r))$ dengan $\quad 1 \in I d(R)$ dan $(-(1-r)) \in U_{r}(R)$. Oleh karena itu, $R$ adalah ring bersih kanan. Selanjutnya, karena $\left(1+r+r^{2}+\ldots+r^{n-1}\right)(1-r)=1$ $\operatorname{maka}\left(1+r+r^{2}+\ldots+r^{n-1}\right)(1-r)=1$ sehingga diperoleh $r=1-(1-r)$.

Karena $(1-r) \in R$ dan $R$ adalah ring maka $(-(1-r)) \in R$, sehingga diperoleh $r=1+(-(1-r))$ dengan $1 \in I d(R)$ dan $(-(1-r)) \in U_{l}(R)$. Oleh karena itu, $R$ adalah ring bersih kiri.

Jadi terbukti bahwa $R=U_{l}(R) \bigcup U_{r}(R) \bigcup N(R)$ adalah ring bersih kanan dan ring bersih kiri.

\section{Kesimpulan}

Berdasarkan pembahasan di atas dapat ditarik kesimpulan sebagai berikut : 1. Setiap ring yang dibangun dari elemen-elemen idempoten adalah ring bersih kanan jika hanya jika ring utamanya merupakan ring bersih kanan.
2. Setiap ring yang merupakan gabungan himpunan semua elemen unit kiri, himpunan semua elemen unit kanan dan himpunan semua elemen nilpoten merupakan ring bersih kanan dan ring bersih kiri.

3. Setiap ring matriks atas ring bersih kanan merupakan ring bersih kanan.

\section{Pustaka}

Călugăreanu.G., 2010, One-sided Clean Rings, Studia Matematica, No.3, vol.55, pp.83-86.

Camillo, V.P., and Anderson, D.D., 2002, Commutative Rings whose elements are a sum of unit and idempotent, Communications in Algebra, No.7, vol.30, pp.33273336.

Han, J., and Nicholson, W. K., 2001, Extensions of clean rings, Comm. Algebra, No.6, vol.29, pp.25892595.

Hazenwingkel,M., Nadiya G., and Kirichenko, V.V., 2005, Algebras, Rings and Modules, vol. 1, Kluwer Academic, New York. 